\title{
Análise da Indústria Brasileira de Software com Base em uma Taxonomia das Empresas: Subsídios para a Política Industrial*
}

\author{
José Eduardo Roselino
}

Economista, professor e pesquisador do Centro Universitário Salesiano de São Paulo - UNISAL

\section{RESUMO}

As atividades de software foram eleitas como opção estratégica da Política Industrial, Tecnológica e de Comércio Exterior - PITCE a partir da identificação de seu papel crescentemente crucial para o desenvolvimento das mais diversas atividades. A política setorial vem sendo desenhada com o objetivo de alcançar duas metas principais: elevar as exportaçôes brasileiras de software e ampliar a participação das empresas nacionais no mercado doméstico.

$\mathrm{O}$ artigo apresenta um panorama da indústria brasileira de software que permite discutir a adequação dos objetivos traçados para a política industrial. A abordagem desenvolvida identifica a expressiva presença das empresas de capital nacional em todos os segmentos considerados, ainda que exibindo grandes assimetrias com relação às empresas de capital estrangeiro. $\mathrm{O}$ quadro apresentado sugere que o enfoque da política deveria centrar-se no reforço aos aspectos

\footnotetext{
* O autor agradece especialmente a João Alberto De Negri da Diretoria de Estudos Setoriais do Instituto de Pesquisa Econômica Aplicada - DISET/IPEA, pela oportunidade de participar do projeto de pesquisa "Estrutura e Dinâmica do Setor de Serviços no Brasil" que possibilitou a realização deste trabalho, aos economistas Antônio Carlos Diegues, Célio Hiratuka e Luiz Esteves pelas sugestões e comentários, assim como aos estatísticos Fernando Freitas e Gustavo Costa pela assessoria técnica e o manuseio dos dados aqui apresentados. Agradece também aos pareceristas anônimos.
} 
virtuosos já existentes na indústria brasileira de software, concentrando a ação das políticas na consolidação das empresas nacionais para o enfrentamento de um mercado crescentemente competitivo.

Palavras-Chave | Indústria de Software; Política Industrial e Tecnológica; Desenvolvimento Industrial

Códigos JEL | L1; L5; L8

\section{ABSTRACT}

The software activities have been elected as a strategic option for the Brazilian Technology, Trade and Industrial Policy - PITCE following the recognition of their increasingly crucial role in the development of other activities. The policy for the software industry has been shaped by two main goals: to raise the Brazilian software exports and to increase the market-share of national firms in the domestic market.

This paper offers an overview of the Brazilian software industry that helps questioning the adequacy of the policy goals for that industry. The approach developed in the paper identifies an expressive number of Brazilian firms in all segments of the software industry, despite the existence of important asymmetries between national and foreign companies. It suggests that policy-making should focus on the reinforcement of virtuous aspects that already can be found in the Brazilian software industry, aiming at the strengthening of national firms to face an increasingly competitive market.

Keywords I Software Industry; Industrial and Technology Policies; Industrial Development

JEL CODES $\quad$ L1; L5; L8 


\section{Introdução}

O lançamento das diretrizes da Política Industrial Tecnológica e de Comércio Exterior - PITCE em novembro de 2003 trouxe o software na condição de "opção estratégica", juntamente com semicondutores, fármacos e bens de capital. A escolha do software, como objeto de atenção prioritária (assim como as demais áreas citadas), teria sido pautada pela consideração de que essa indústria envolve atividades que cumprem os requisitos necessários, que seriam (Carvalho Jr., 2005:22):

a) apresentam dinamismo crescente e sustentável;

b) são intensivos em pesquisa e desenvolvimento ( $P \& D)$;

c) relacionam-se diretamente com a inovação de processos, produtos e formas de uso;

d) têm efeito indutor de melhorias em outras cadeias produtivas; e

e) apresentam potencial para o desenvolvimento de vantagens comparativas dinâmicas.

Essa perspectiva sugere que a proposta de política industrial reconhece a importância da presença transversal do software em diversas cadeias produtivas, como promotor de efeitos transformadores sobre outras atividades econômicas. O potencial dinamizador do software, como elemento crescentemente crucial na introdução e difusão de inovações em diversas atividades econômicas, tornao merecedor de tratamento privilegiado por parte de políticas de desenvolvimento industrial e tecnológico.

As possibilidades de articulação dos objetivos de desenvolvimento do software com os das outras "opções estratégicas" são substantivas. O adequado desenvolvimento das atividades voltadas aos semicondutores, bens de capital e mesmo fármacos envolve certamente funções intensivas em tecnologias de software. No software reside também um importante potencial a ser direcionado às outras dimensões das políticas públicas, que se dariam com o desenvolvimento de aplicações voltadas aos serviços de educação, saúde e gestão pública, por exemplo. Essa transversalidade do software em várias cadeias produtivas resulta na oportunidade de se desenvolver a política de forma articulada, explo- 
rando-se especialmente a "nítida relação entre as políticas para semicondutores, software e bens de capital com a política de infra-estrutura (energia, logística e saneamento, e telecomunicações, respectivamente)" (Governo Federal, 2003:16). As atividades de desenvolvimento de software devem ser estimuladas em articulação com aquelas voltadas aos semicondutores, integrando-os às "partes lógicas" de máquinas industriais, no desenvolvimento de tecnologias voltadas à “TV Digital”, ou ainda na "infomedicina”, por exemplo.

Pode-se afirmar que o conjunto das medidas planejadas (algumas já em operação) no âmbito da PITCE ${ }^{1}$ representa uma importante evolução no sentido de uma política articulada para o desenvolvimento da indústria brasileira de software. O desenho geral da política, assim como a mobilização articulada de diferentes atores, sinalizam o amadurecimento da visão dos gestores com relação à importância das atividades de software, assim como suas especificidades.

No documento instituidor dessas diretrizes (Governo Federal, 2003) são apresentadas duas metas norteadoras da política para o software: transformar o Brasil em referência na exportação de software e serviços correlatos, e promover uma "ampliação significativa" da presença das empresas nacionais no mercado interno. A meta de exportação é apresentada como foco central do programa em documento posterior do governo, explicitando os objetivos da PITCE, assim como sintetizando os principais avanços em sua implementação:

Com uma meta de elevar as exportaçôes de software dos atuais US\$100 milhões para US\$ bilhões num horizonte de quatro anos, o programa começou a articular um vasto conjunto de açôs, entre as quais cumpre destacar: mudança do regime do PIS/CONFINS para o setor, reformulação do programa de apoio à indústria de software - Prosoft do Banco Nacional de Desenvolvimento Econômico e Social-BNDES, equacionamento de um programa de qualidade de software, incluindo normalização e certificação (com o Instituto Nacional de Metrologia, Normalização e Qualidade Industrial INMETRO funcionando como organismo acreditador de certificadoras), e investimentos públicos em projetos de C\&T, adotando-se o software como área prioritária nos Fundos Setoriais (MDIC, 2005:13). 
O objetivo de expansão da comercialização no exterior parece ter sido inspirado no desempenho exportador de outros países não-centrais, conforme sugere o documento original de diretrizes da PITCE:

O software brasileiro precisa adquirir competitividade internacional num mercado em grande expansão, como alguns casos bem-sucedidos de exploração de oportunidades por paises em desenvolvimento como India, Israel e Irlanda (Governo Federal, 2003:19).

Já a meta de expansão da participação das empresas nacionais no mercado doméstico até 2007 não aparece vinculada a nenhum objetivo quantitativo nos documentos oficiais. ${ }^{2}$ É natural que os documentos públicos existentes sobre a PITCE apresentem os objetivos num plano mais geral, uma vez que se dedicam mais ao anúncio das "diretrizes norteadoras" da política estatal. No entanto, chama a atenção a ausência na literatura consultada, inclusive naquelas vinculadas às instituiçõos públicas responsáveis pela gestão e execução da política, de indicadores mais precisos da participação da empresa nacional na atual configuração do mercado doméstico, dificultando o estabelecimento de metas mais precisas a serem perseguidas pela política.

Esse objetivo da política parece pautar-se na avaliação de que a participação das empresas nacionais é minoritária, uma vez que estimativas nessa direção são freqüentes na literatura. A origem dessas estimativas, que sugerem uma participação das empresas nacionais inferior a 25\%, é possivelmente a observação de rankings das maiores empresas em segmentos específicos, nos quais as empresas estrangeiras são largamente predominantes. ${ }^{3}$ Petit (2005:22), por exemplo, aponta que "a participação da empresa brasileira não deve ultrapassar 20\%". Convém apontar que essas estimativas não convergem com os dados que foram encontrados na pesquisa que se realizou para a execução deste trabalho, conforme será apresentado a seguir.

Os objetivos relativos à ampliação da presença das empresas nacionais no mercado interno devem merecer, portanto, um tratamento mais atento. Essa

\footnotetext{
2 Em material apresentado em palestra pelo coordenador-geral de Software e Serviços da Secretaria de Política de Informática-MCT, Antenor Corrêa, sugere-se a meta de ampliar a participação das empresas nacionais para "pelo menos $25 \%$ até $2007 "$ (Corrêa, 2005).

3 Como por exemplo, Arbache (2002) e Stefanuto (2004).
} 
meta deverá ser mais bem avaliada a partir de estudos específicos, voltados à identificação da presença das empresas nacionais nos diferentes segmentos ou nichos do mercado de software, permitindo a eleição de áreas prioritárias para uma política mais focalizada. Para tanto, sugere-se a necessidade de um esforço coletivo, mobilizando especialistas do governo e da comunidade científica/acadêmica para estudos dedicados ao diagnóstico da situação e potencialidade das empresas nacionais nos principais mercados ou "áreas de aplicação" do software.

Ainda que esteja baseado numa perspectiva panorâmica da indústria brasileira de software, o presente trabalho permite já algum avanço nesse sentido, sugerindo inclusive que a participação das empresas nacionais é substancialmente maior do que se supõe usualmente. A análise que se apresenta a seguir, parte de um procedimento que permite o agrupamento das empresas em três "grandes segmentos" da indústria de software, identificando a existência de um "padrão" para a participação relativa das empresas nacionais e estrangeiras no mercado brasileiro.

Na próxima seção apresenta-se o panorama da indústria brasileira de software e serviços correlatos por meio da exploração e manuseio de microdados originais, a partir de uma taxonomia das empresas atuantes no mercado brasileiro de software.

\section{Panorama das atividades de desenvolvimento de software e serviços de informática no Brasil}

As estatísticas existentes relativas às atividades de software são sempre passíveis de fragilidades, sendo freqüente a existência de discrepâncias significativas, de acordo com os critérios assumidos nas diferentes abordagens. ${ }^{4}$ Além das dificuldades de mensuração decorrentes da natureza imaterial e intangível do software, a própria definição dos contornos da indústria é tarefa particularmente problemática. A transversalidade do software nas diversas cadeias produtivas faz com que estas atividades estejam dispersas pelos mais diversos setores econômicos.

Este trabalho apresenta um esforço de caracterização da indústria brasileira de software, considerando-se apenas os valores envolvidos pelas atividades de

4 Destaca-se a iniciativa em desenvolvimento no âmbito da OCDE para a padronização das informações estatísticas
referentes à indústria de software $(O C D E, 2004 a)$. 
empresas especificamente voltadas ao desenvolvimento e comercialização de software (serviços e produtos). Isso significa aceitar que um importante conjunto de atividades de software desenvolvido em outras empresas (pertencentes às indústrias de teleequipamentos e de eletrônicos de consumo, por exemplo) é deixado de lado.

A abordagem quantitativa desenvolveu-se com base no manuseio de informações junto à base de microdados da Pesquisa Anual de Serviço (PAS/IBGE) associada a outras fontes estatísticas reunidas por iniciativa da Diretoria de Estudos Setoriais do Instituto de Pesquisa Econômica Aplicada - DISET/IPEA. ${ }^{5}$ Os dados obtidos subsidiam uma leitura qualitativa do setor, apoiada na literatura existente, assim como em outras pesquisas que envolveram visitas junto a empresas nacionais e estrangeiras voltadas às tecnologias de informação e comunicação. ${ }^{6}$

A taxonomia foi elaborada a partir da investigação e manuseio das informaçôes referentes às fontes de receita das empresas existentes no questionário suplementar da PAS para as empresas com mais de 20 empregados. Pretende-se com isso incorporar à análise a possibilidade de um tratamento mais adequado ao heterogêneo conjunto de atividades que compõem a indústria de software, com a identificação de três segmentos principais (a saber, serviços em software de baixo valor, serviços em software de alto valor e software-produto). Este recurso permite um tratamento diferenciado das informaçóes relativas aos grupos de empresas pertencentes a segmentos com dinâmicas fundamentalmente distintas.

Complementarmente, incorpora-se à análise um segundo "corte", com a diferenciação baseada na origem do capital da empresa, agrupando as empresas de capital predominantemente nacional privado, as nacionais públicas e, ainda, o conjunto das empresas transnacionais (com base no Censo de Capitais Estrangeiros do Banco Central do Brasil). Esse procedimento permite estimar a proporção relativa do mercado, em cada segmento, que cabe ao conjunto das

\footnotetext{
Nos últimos dez anos o IPEA tem organizado o maior conjunto de informações sobre as empresas no Brasil. Ver detalhes sobre a construção deste banco de dados em De Negri \& Salerno (2005).

6 Projeto "Diretório de Pesquisa Privada" no convênio FINEP/GEEIN (Grupo de Estudos em Economia Industrial), o Projeto: "Perspectivas de Reestruturação das Políticas de Financiamento do Desenvolvimento Tecnológico no Brasil" no Convênio FINEP (Financiadora de Estudos e Projetos)/FUNDAP (Fundação para o Desenvolvimento Administrativo), assim como o acompanhamento do Projeto de Iniciação Científica "Um estudo das atividades de software desenvolvidas no pólo de Tecnologia de Informação e Comunicação da região de Campinas", de A.C. Diegues, junto à Fundação de Amparo à Pesquisa do Estado de São Paulo - FAPESP (Processo 03/07816-4).
} 
empresas nacionais (públicas e privadas), assim como uma análise comparativa dos indicadores gerais de cada conjunto.

A indústria brasileira de software envolve valores que são suficientes para evidenciar sua relevância econômica. Sua importância, conforme já argumentado, não se restringe aos valores relativos ao faturamento geral da indústria, mas deve levar em conta a sua importância como elemento dinamizador da estrutura produtiva em geral, advinda de sua presença pervasiva ${ }^{7}$ e transversal nas mais diversas cadeias produtivas.

A heterogeneidade das empresas voltadas às atividades de serviços de informática justifica a opção por uma primeira aproximação a partir de critérios bastante abrangentes, considerando-se como parte do universo de empresas analisadas, todas aquelas classificadas como sendo prestadoras de serviços de informática (Tabela 1).

TABELA 1

Empresas voltadas às atividades de desenvolvimento de software

e serviços de informática por CNAE (2002)

Classificação Nacional de Atividades Econômicas - CNAE

CNAE 7210 - Consultoria em Hardware

CNAE 7220 - Consultoria em Software (Desenvolvimento

e Edição de Software Pronto para o Uso e Software sob

Encomenda)

CNAE 7230 - Processamento de Dados

CNAE 7240 - Atividades de Banco de Dados e

Distribuição on-line de Conteúdo Eletrônico

CNAE 7250 - Manutenção e Reparação de Máquinas

de Escritório e de Informática

Total
Número de empresas

8.071

10.064

24,4

12.330 29,9

93

Fonte: elaboração própria com base nos microdados da PAS/IBGE.

7 Originado do inglês pervasive (oriundo originalmente do latim: pervasus, particípio passado de pervadere); adjetivo adotado neste trabalho diante da ausência de um vocábulo em língua portuguesa capaz de expressar simultaneamente o caráter disseminado e penetrante do software. 
Os dados obtidos indicam que, em 2002, existiam mais de 40 mil empresas voltadas a essas atividades, com uma distribuição relativamente uniforme dentre quatro das classificaçôes consideradas, assim como a existência de poucas empresas situadas na CNAE 7240. Essa primeira aproximação ampara-se numa leitura baseada em todas as empresas classificadas como sendo voltadas aos "serviços de informática”, incluindo-se então empresas pertencentes às CNAES 7210 e 7250 que não pertenceriam ao "núcleo" da indústria brasileira de software (que estariam a rigor nas empresas das CNAES 7220 e 7230). ${ }^{8}$

A Tabela 2 mostra o número de pessoas ocupadas nessas atividades, evidenciando-se que a partir deste critério abrangente, as atividades de desenvolvimento de software e serviços de informática associados mobilizam um grande contingente de empresas e geram um significativo número ocupações. ${ }^{9}$ Observa-se também que a maioria dessas empresas, assim como do pessoal ocupado, encontra-se concentrada nos estados das regiôes Sudeste, Centro-Oeste e Sul. Praticamente $80 \%$ da receita operacional líquida total oriunda dessas atividades estão na Região Sudeste, onde encontram-se também cerca de $71 \%$ das empresas e $61 \%$ das ocupações.

É interessante notar também que nessa mesma região localizam-se as empresas com maior produtividade, indicada pelo faturamento por pessoa ocupada. Em média, nas empresas localizadas na Região Sudeste, a receita operacional líquida obtida por cada pessoa ocupada é mais do que o dobro do valor encontrado em outras regiōes.

Outro aspecto relevante apresentado pela Tabela 2 são os números relativos à Região Centro-Oeste, que aparece como a segunda maior em termos de receita total, assim como pessoal ocupado. Essa região caracteriza-se ainda pelo maior tamanho relativo médio das empresas, medido tanto pela receita operacional líquida média das empresas (mais do que o dobro da média geral), assim como pelo número médio de pessoas ocupadas por empresa (com quase o quádruplo da média do setor).

\footnotetext{
8 Num momento posterior as empresas (independentemente da CNAE) serão agrupadas em quatro categorias, a partir de tipologia definida pelo autor, com base na origem predominante na formação de sua receita, identificando-se então aquelas que seriam voltadas prioritariamente ao desenvolvimento de software.

9 Optou-se neste trabalho pela consideração de "Pessoal Ocupado" (em que se contabiliza não apenas trabalhadores formalmente assalariados, mas também os terceirizados, autônomos e estagiários) como melhor indicador do número de trabalhadores envolvidos nesta indústria, uma vez que são freqüentes as práticas de contratações precarizadas.
} 
TABELA 2

Dados gerais sobre as atividades de desenvolvimento de software e serviços associados por região geográfica (valores em reais - 2002)

\begin{tabular}{|c|c|c|c|c|c|c|c|c|c|}
\hline & $\begin{array}{c}\text { Receita } \\
\text { líquida total } \\
\text { (a) }\end{array}$ & $\%$ & $\begin{array}{l}\text { Número de } \\
\text { empresas } \\
\text { (b) }\end{array}$ & $\%$ & $\begin{array}{l}\text { Pessoal } \\
\text { ocupado } \\
\text { (c) }\end{array}$ & $\%$ & $a / b$ & $a / c$ & $c / b$ \\
\hline 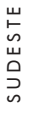 & 15.955 .217 .994 & 79,34 & 29.402 & 71,26 & 157.344 & 61,79 & 542.639 & 101.403 & 5,35 \\
\hline$\vec{\jmath}$ & 1.428 .668 .055 & 7,10 & 6.653 & 16,12 & 32.901 & 12,92 & 214.740 & 43.423 & 4,95 \\
\hline 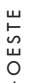 & & & & & & & & & \\
\hline 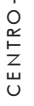 & 2.085 .955 .576 & 10,37 & 1.923 & 4,66 & 45.002 & 17,67 & 1.084 .740 & 46.353 & 23,40 \\
\hline $\begin{array}{l}\text { 崩 } \\
\text { o } \\
\text { z }\end{array}$ & 69.911 .918 & 0,35 & 305 & 0,74 & 2.076 & 0,82 & 229.219 & 33.676 & 6,81 \\
\hline $\begin{array}{l}\text { w } \\
\stackrel{5}{u} \\
\stackrel{2}{0} \\
\alpha \\
0 \\
z\end{array}$ & 569.603 .496 & 2,83 & 2.975 & 7,21 & 17.327 & 6,80 & 191.463 & 32.874 & 5,82 \\
\hline $\begin{array}{l}\vec{\leftarrow} \\
\stackrel{\mathbb{O}}{0}\end{array}$ & 20.109 .357 .039 & 100 & 41.258 & 100 & 254.650 & 100 & 487.393 & 78.969 & 6,17 \\
\hline
\end{tabular}

Fonte: elaboração própria com base nos microdados da PAS/IBGE.

Para avançar na compreensão das características da indústria brasileira de software as empresas atuantes no mercado brasileiro foram reunidas em quatro diferentes grupos de acordo com as fontes predominantes na composição da receita, independentemente da sua classificação CNAE. O procedimento adotado permitiu classificar as empresas de serviços em informática em quatro categorias: Categoria 1, empresas voltadas ao desenvolvimento de serviços de 
informática não-intensivos em software; Categoria 2, empresas voltadas a serviços em software de baixo valor; Categoria 3, empresas voltadas a serviços em software de alto valor e; Categoria 4, empresas voltadas ao desenvolvimento e comercialização de software-produto ou pacote (Quadro 1). ${ }^{10}$

\section{QUADRO 1}

Apresentação das categorias das empresas definidas a partir da tipologia proposta segundo a fonte de receita predominante

Categoria

Categoria 1 :

Serviços de informática

Categoria 2:

Serviços em software

(baixo valor agregado)

Categoria 3:

Serviços em software

(alto valor agregado)

Categoria 4:

Desenvolvimento e comercialização de software-produto
Descrição das atividades principais das empresas:

Consultoria em hardware (configurações e redes), serviços de manutenção e reparação e outras atividades relacionadas à Informática, inclusive comercialização de equipamentos.

Serviços ligados à Internet (exceto provedores de acesso), criação e manutenção de bancos de dados, processamento de dados para terceiros, suporte e terceirização.
Desenvolvimento e produção de software pronto para uso (inclusive customização), comercialização, licenciamento e locação de software pronto para uso (inclusive de terceiros).

Fonte: elaboração própria.

${ }^{10}$ Esta classificação foi desenvolvida a partir do manejo dos dados do "Suplemento Serviços de Informática" da Pesquisa Anual de Serviço (PAS/IBGE - 2002), aplicado censitariamente às empresas com 20 ou mais pessoas empregadas. A categoria da empresa foi determinada de acordo com o grupo de fontes de receita predo ategoria $1=\sum$ (Cod02,..,05; 22,..., 29), Categoria $2=\Sigma(\operatorname{Cod} 10, . ., 21)$, Categoria $3=\sum(\operatorname{Cod} 08,09)$, Categoria $4=\Sigma(\operatorname{Cod} 06, . ., 07 ; 30)$. 
As empresas típicas da Categoria 1 estariam voltadas principalmente ao desenvolvimento de atividades de informática com menor conteúdo em desenvolvimento de software. São empresas de serviços em informática com ênfase na manutenção e comercialização de hardware e não são o foco central deste trabalho, ou seja, a indústria brasileira de software.

Dentre as categorias analisadas, são de particular interesse para este artigo aquelas voltadas ao desenvolvimento de software, representadas pelas categorias de números 2, 3 e 4. Pode-se afirmar que é este o conjunto de empresas, que tem nas atividades de desenvolvimento de software a sua principal fonte de receita, que compõe a Induistria Brasileira de Software. As empresas classificadas como sendo voltadas aos serviços em software de baixo valor (Categoria 2) estariam direcionadas ao desenvolvimento de funçōes menos complexas. Dentre as diversas atividades que compõem a indústria de software, os serviços de baixo valor ${ }^{11}$ são certamente os menos densos em termos tecnológicos. As atividades classificadas nesta categoria são normalmente caracterizadas por rotinas repetitivas ou funções que não dependem de significativos conhecimentos específicos. Esses serviços incluem atividades rotineiras de codificação, alimentação de sistemas de informação, especialmente aqueles relacionados com a manutenção e processamento de banco de dados para terceiros, como lista de assinantes de serviços telefônicos, clientes de seguradoras ou usuários de serviços públicos, assim como atividades de baixo conteúdo tecnológico de manutenção e atualização de sítios de Internet.

Os serviços executados revelam a clara separação entre a concepção (centrada no demandante do serviço) e a execução (desenvolvida pela empresa prestadora), que exige normalmente apenas o domínio de conhecimentos codificáveis, obteníveis com a formação técnica em programação. Ou seja, o serviço de baixo valor agregado

(...) envolve normalmente aspectos como a manutenção de software ou a geração de códigos. São serviços que demandam conhecimentos mais básicos de programação. As tarefas a desenvolver costumam ser simples e bem especificadas pelo cliente (Salatti, 2004:30).

\footnotetext{
Adota-se nesse trabalho um cuidado especial ao se diferenciar os "serviços em software" de outros "serviços em informática" que freqüentemente são apresentados de forma indiferenciada. "Serviços em informática" incluiriam também atividades como consultorias em hardware (configurações e redes), manutenção e reparação de equipamentos, entre outros.
} 
De modo geral, essas atividades são intensivas em mão-de-obra de média qualificação (muitas vezes de perfil técnico), e apresentam pequenas possibilidades de ganhos de escala. O determinante fundamental da competitividade é o custo do desenvolvimento, estreitamente vinculado ao custo da mão-deobra. A natureza desses serviços, caracterizada pela inexistência de restriçóes tecnológicas relevantes, assim como o conteúdo pouco intensivo em conhecimentos específicos, resulta em menores possibilidades de diferenciação dos produtos/serviços, e no predomínio da concorrência baseada em preço. Por essas razões, este segmento é, dentre todos que compõem a tipologia proposta, aquele que apresenta menores barreiras à entrada.

Dentre os serviços em software, denomina-se como sendo de alto valor (Categoria 3) aqueles que incluem etapas mais complexas do desenvolvimento de uma solução em software. São etapas que envolvem freqüentemente conhecimentos específicos de engenharia de software e análise de sistemas. Essas etapas estão situadas na parte hierarquicamente superior das funções desempenhadas pela indústria de software, e representam as tarefas mais complexas do processo de produção do software. São atividades que incluem o design de alto nível abrangendo os projetos e a modelagem da arquitetura de soluçóes em aplicações de software, assim com de bancos de dados complexos. Estas atividades envolvem, portanto, um conjunto mais complexo de funções, assim como o domínio de processos mais intensamente tecnológicos.

Freqüentemente, os serviços de alto valor são referidos como sendo software sob encomenda, sugerindo o desenvolvimento de todas as etapas do processo de produção do software, o que incluiria, então, as fases da análise, projeto, programação (codificação), testes, implantação e documentação. Neste trabalho optouse pela denominação de serviços de alto valor por se considerar que algumas empresas, em sistemas produtivos descentralizados, concentram-se nessas funções mais densamente tecnológicas sem desenvolver as outras funções, ou seja, o software propriamente.

Salatti define o serviço de alto valor como sendo aquele que incorpora

(...) conhecimentos e capacidades mais abrangentes, que envolvem ações desde a análise de requisitos do cliente até o conhecimento de regras do negócio. Envolvem incerteza relativa ao resultado ou partilha de responsabilidade na definição do sistema (2004:30). 
Ou seja, diferentemente dos serviços de baixo valor, em que o custo de desenvolvimento é o fator determinante, "as empresas de software sob encomenda têm na imagem de confiabilidade, na interação com o usuário e na sofisticação dos mercados locais as suas características mais marcantes" (Rocha, 1998:3). As empresas voltadas ao desenvolvimento de serviços de alto valor assumem a responsabilidade por funções complexas, muitas vezes críticas para as atividades das empresas demandantes. Essa relação exige normalmente uma estreita interação entre as partes.

Nessa atividade ganham crescente importância os retornos de escala, uma vez que são cada vez mais intensas as práticas de componentização e reuso de módulos ou partes de programas. Saur destaca a importância dessas técnicas: "para conquistar mercado e segurá-lo, o software-serviço oferecido terá cada vez mais de possuir escalabilidade e componentização para reusabilidade"(2004:50). Nesse aspecto, as empresas já estabelecidas com uma ampla base de clientes constroem sólidas vantagens competitivas associadas ao portfolio de partes e módulos reutilizáveis que pode dispor em sua "biblioteca" de componentes. As técnicas de reuso permitem ganhos expressivos nos custos finais do software a ser desenvolvido, assim como o encurtamento do prazo de desenvolvimento. Assim, verifica-se uma importância crescente de economias de escala, apropriáveis especialmente por empresas com maior base de clientes. Esse fator conjuga-se então com uma maior complexidade das atividades envolvidas, e com o caráter mais restritivo dos conteúdos tecnológicos, resultando em elementos de reforço a concentração dos mercados e elevadas barreiras à entrada de novos competidores.

Dentre os três segmentos da indústria de software na taxonomia adotada, o de software-produto ou pacote (Categoria 4) é aquele em que a dinâmica competitiva se diferencia com mais nitidez das características concorrenciais típicas do setor de serviços. Aqui o software é comercializado à semelhança de uma mercadoria "material", muitas vezes exposto em prateleira. Nesse segmento os retornos crescentes de escala desempenham um papel fundamental para o sucesso de qualquer produto.

Software-pacote é uma aplicação preparada previamente que serve a um conjunto amplo de clientes. (...) Neste segmento, a competitividade é definida pela capacidade de desenvolvimento técnico e de comercialização de 
produtos em massa. É alto o investimento necessário para desenvolver e lançar o produto, e o retorno depende de sua aceitação pelo mercado (Melo \& Castello Branco, 1997:2).

O desenvolvimento de software-produto envolve, de modo geral, uma menor interação entre a empresa de software o o potencial demandante, uma vez que este produto não é voltado ao atendimento das necessidades de nenhum usuário particular, mas de um conjunto mais ou menos homogêneo. Alguns produtos (horizontais) são voltados ao atendimento do conjunto do mercado, independentemente de qualquer especificidade da atividade envolvida pelo potencial usuário. Outros (verticais) desempenham funções especificamente voltadas às necessidades de setores particulares. No entanto, em ambos casos, a existência do software-produto pressupõe a existência de uma base de consumidores razoavelmente ampla para diluir os custos de desenvolvimento, de modo geral elevados.

O software-produto representa um negócio distinto, com produtos padronizados produzidos no interior de uma empresa de software em isolamento com relação a consumidores específicos, e distribuido para muitos consumidores por meio de diversos canais de comercialização (OCDE, 2004b:21).

A amplitude da base instalada de um determinado produto em software determina também, em muitos casos em que há interatividade entre diferentes equipamentos ou sistemas, os efeitos de rede relativos a imposição de padrões tecnológicos dominantes, reforçando ainda mais o poder de mercado de empresas já estabelecidas. Essas características explicam a predominância de uma forte tendência atuando em direção à convergência a padrões dominantes e concentração das estruturas de mercado.

Além deste corte definido a partir da predominância de fontes da receita das empresas, emprega-se a diferenciação das empresas por origem do capital separando-se as empresas estrangeiras, das nacionais privadas e públicas. ${ }^{12}$

\footnotetext{
12 A diferenciação entre as empresas nacionais privadas das públicas (onde se agrupam as estatais, autarquias, companhias e fundações municipais, estaduais e federais) foi possível mediante o cruzamento dos dados da PAS com a base de dados RAIS (foram consideradas empresas públicas aquelas que tinham os seguintes códigos para o "tipo jurídico": 1996, 1112 , $1104,1120,2011,2020,1147,1139,1155,1023,1015,1031,1082,1074,1058,1074,1058,1040,1066)$.
} 
A partir do emprego conjugado desses dois critérios de classificação (fonte predominante de receita para a empresa e origem do capital) tem-se a construção de taxonomia com dez diferentes grupos (inexistem empresas públicas nas Categorias 3 e 4), dentre as quais estão distribuídas 985 empresas, sendo 96 estrangeiras, 20 públicas e 879 nacionais privadas (Tabela 3).

Vale destacar que o conjunto dessas quase mil empresas (todas com 20 ou mais empregados) era responsável pela parte majoritária dos valores envolvidos no setor em estudo, respondendo por uma receita operacional líquida total de mais de $\mathrm{R} \$ 13,5$ bilhões no ano de 2002 , ou seja, $86,5 \%$ da receita operacional líquida total das empresas constantes da "base depurada" (que apresentou receita operacional líquida total de $\mathrm{R} \$ 15,7$ bilhões para um universo de 10.457 empresas).

TABELA 3

Distribuição das empresas a partir da tipologia proposta segundo a fonte de receita predominante e origem do capital

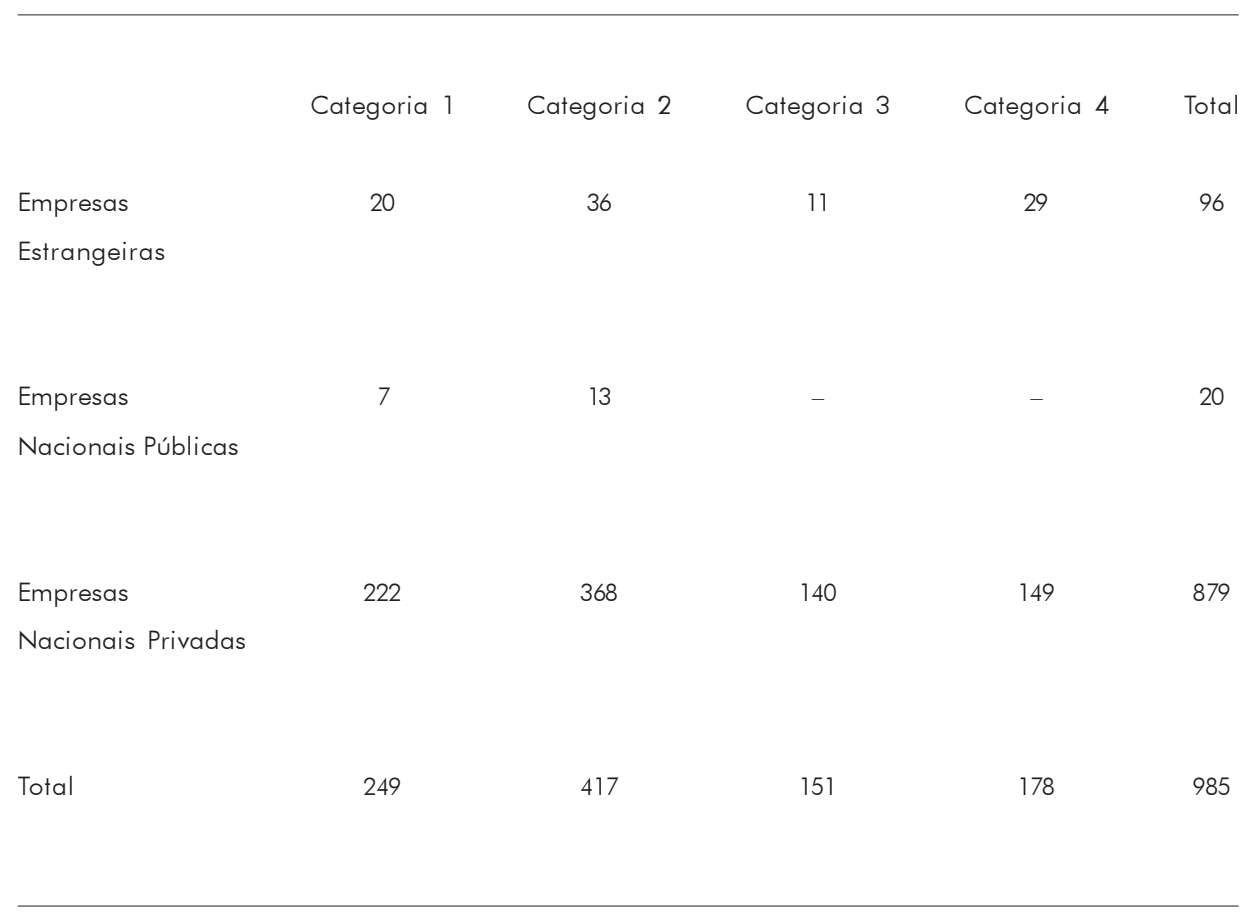

Fonte: elaboração própria com base nos microdados da PAS e RAIS (2002). 
A análise das estatísticas descritivas relacionadas à taxonomia proposta permite também a confirmação dos elementos apontados, e proporcionam outras considerações relevantes. O Quadro 2 apresenta a "matriz de categorias" elaborada a partir dos critérios expostos, assim como a abordagem desenvolvida. A leitura desses dados permite uma aproximação bastante confiável e representativa da realidade das empresas componentes da indústria brasileira de software. A utilização desta tipologia permite o exame da realidade da indústria a partir de diferentes cortes, com a possibilidade de se empreender leituras panorâmicas de cada segmento (análises latitudinais), dos grupos de empresas definidos pela origem predominante do capital (análises longitudinais), assim como uma análise global dos números para todo o conjunto.

QUADRO 2

Apresentação da "matriz de categorias" e as abordagens analíticas ("latitudinais" e "longitudinais")

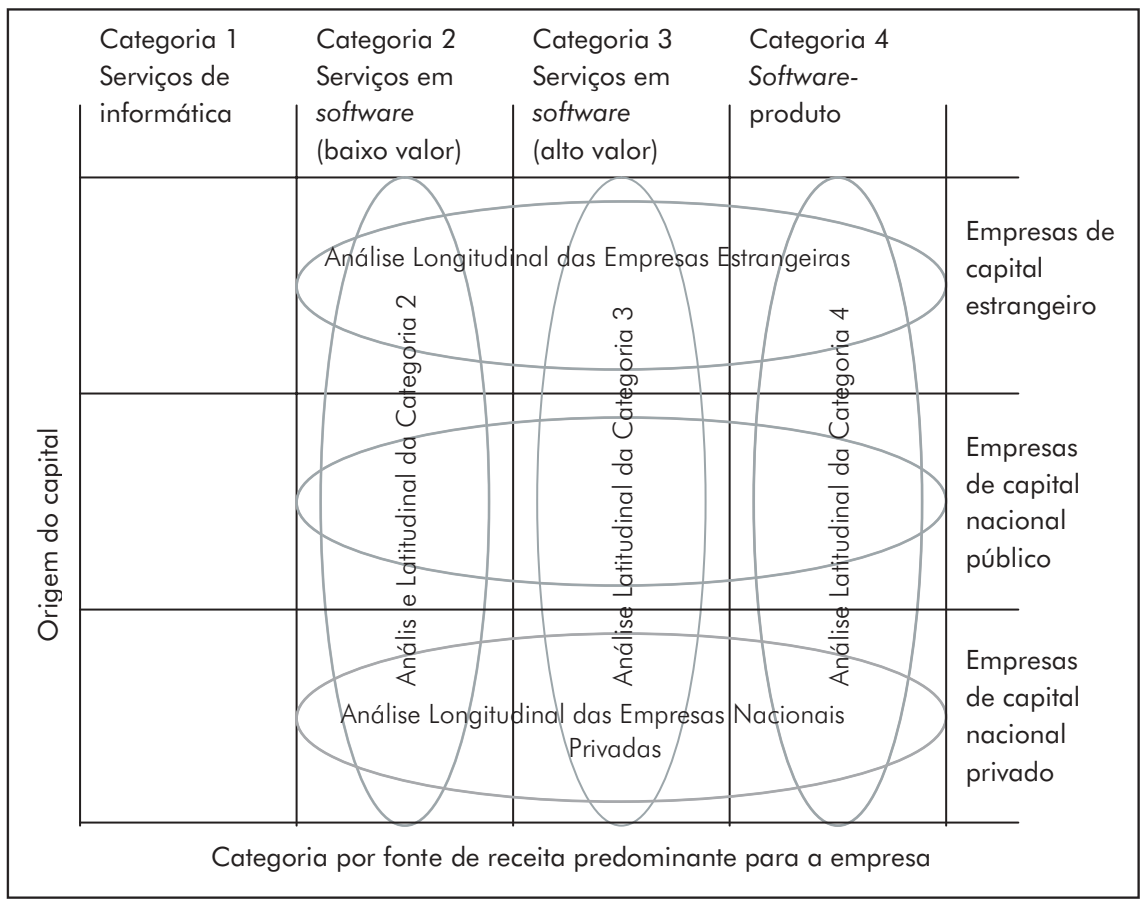

Fonte: elaboração própria com base nos microdados da PAS e RAIS (2002). 


\subsection{Análise longitudinal: as empresas nacionais privadas de software}

A base de dados apontou a existência de mais de 650 empresas nacionais privadas voltadas primariamente ao desenvolvimento de software. ${ }^{13}$ A receita operacional líquida total dessas empresas correspondia a pouco mais de $\mathrm{R} \$ 5,5$ bilhões no ano de 2002, representando cerca de 55\% da receita operacional líquida total do mercado brasileiro de software a partir do critério proposto nesta classificação. ${ }^{14}$ Existe um predomínio de empresas voltadas ao segmento de serviços de baixo valor agregado, que concentra 56\% das empresas (Tabela 4).

O caráter fortemente intensivo em mão-de-obra que caracteriza as atividades de serviços de baixo valor agregado resulta na existência de um número de pessoas ocupadas mais que proporcional ao número de empresas voltadas a estas atividades. As atividades compreendidas nessa categoria demandam grande número de trabalhadores, freqüentemente com formação de nível médio, voltado ao desenvolvimento de atividades rotineiras de digitação e alimentação de bancos de dados, ou ainda a programação (ou codificação) de rotinas predeterminadas.

A existência de um maior número de empresas nacionais privadas voltadas a serviços em software de baixo valor se explica pela existência de baixas barreiras à entrada nesse segmento. Conforme já se indicou, as vantagens de escala desempenham papel pouco relevante nesse segmento, proporcionando condiçôes menos desvantajosas de concorrência para as empresas nacionais privadas (em geral menores que as estrangeiras). Ademais, a baixa complexidade tecnológica das operações envolvidas, assim como a inexistência de barreiras associadas a padrões tecnológicos dominantes, também resultam em menores dificuldades para o ingresso nesse segmento. Esses elementos, assim como a importância determinante da relação entre vendedor/desenvolvedor e comprador/encomendante possivelmente conferiram às empresas locais (muitas vezes pequenas e médias empresas) posiçôes mais confortáveis nos mercados de serviços de baixo valor agregado. As empresas nacionais privadas encontram nesses segmentos de serviços de baixo

\footnotetext{
${ }^{13}$ Uma vez mais convém reforçar que esta análise foi elaborada com base em um questionário suplementar da Pesquisa Anual de Serviços aplicado censitariamente às empresas com 20 ou mais funcionários empregados.

${ }^{14}$ A receita operacional líquida das empresas (nacionais públicas e privadas e estrangeiras) nas categorias de serviços em software (baixo e alto valor) e software-produto para o ano 2002 totalizou pouco mais de R\$10,3 bilhões.
} 
TABELA 4

Caracterização das empresas nacionais privadas de software

valores em R\$ milhões (2002)

\begin{tabular}{ccccc}
\hline & $\begin{array}{c}\text { Serviços em } \\
\text { software } \\
\text { (baixo valor) }\end{array}$ & $\begin{array}{c}\text { Serviços em } \\
\text { software } \\
\text { (alto valor) }\end{array}$ & $\begin{array}{c}\text { Software- } \\
\text { produto }\end{array}$ & Total \\
Número de empresas & 368 & 140 & 149 & 657 \\
$\%$ & $56 \%$ & $21 \%$ & $23 \%$ & $100 \%$ \\
Receita líquida total & 3.800 & 968 & 894 & $100 \%$ \\
Pessoal ocupado & $67 \%$ & $17 \%$ & $16 \%$ & 77.793 \\
$\%$ & 60.082 & $12 \%$ & 8.274 & $100 \%$ \\
\hline
\end{tabular}

Fonte: elaboração própria com base nos microdados das empresas PAS e RAIS.

valor agregado um ambiente propício para o estabelecimento de negócios que são relativamente preservados de uma concorrência mais intensa com empresas estrangeiras.

Por outro lado, percebe-se a existência de um considerável número de empresas nacionais atuantes nos segmentos de serviços de alto valor agregado, assim como de software-produto. Este quadro evidencia a natureza heterogênea da indústria brasileira de software, caracterizada também por um significativo conjunto de empresas inseridas nos segmentos mais dinâmicos. A presença de quase 300 empresas nesses dois segmentos (serviços de alto valor agregado e softwareproduto) reforça a percepção da atuação de um significativo conjunto de empresas nacionais nos segmentos em que o conteúdo tecnológico é mais intenso.

A Tabela 5 apresenta outros elementos relevantes para reflexão, confirmando os argumentos deste trabalho. Percebe-se que as empresas brasileiras privadas voltadas ao desenvolvimento de serviços de baixo valor agregado são em média maiores (em termos de receita operacional líquida média e pessoal ocupado), do 
que aquelas que são voltadas aos segmentos mais dinâmicos, o que possivelmente se explique pelo ambiente mais confortável para o desenvolvimento de seus negócios, marcado por menores pressões competitivas por parte de concorrentes estrangeiros.

Identifica-se, no entanto, que as empresas brasileiras privadas voltadas ao desenvolvimento de atividades classificadas como mais intensivas em escala e conteúdo tecnológico apresentam uma produtividade bastante superior, indicada pelo valor médio da receita operacional líquida obtida por pessoa ocupada.

TABELA 5

Caracterização das empresas nacionais privadas de software valores médios em R\$ (2002)

\begin{tabular}{lcccc}
\hline & $\begin{array}{c}\text { Serviços em } \\
\text { software } \\
\text { (baixo valor) }\end{array}$ & $\begin{array}{c}\text { Serviços em } \\
\text { software } \\
\text { (alto valor) }\end{array}$ & $\begin{array}{c}\text { Software- } \\
\text { produto }\end{array}$ & $\begin{array}{r}\text { Média } \\
\text { geral }\end{array}$ \\
Receita líquida média & 10.328 .643 & 6.914 .922 & 6.002 .344 & 8.620 .059 \\
Pessoal ocupado médio & 163 & 67 & 56 & 118 \\
Receita líquida per capita & 63.263 & 102.584 & 108.092 & 72.801 \\
\hline
\end{tabular}

Fonte: elaboração própria com base nos microdados da PAS e RAIS.

As empresas nacionais privadas voltadas ao desenvolvimento de softwareproduto exibem, a despeito de uma receita operacional líquida média menor, uma receita operacional líquida de R \$ 108 mil por pessoa ocupada, 48,4\% superior à média geral das empresas nacionais privadas e 70,8\% superior à média do grupo de empresas voltadas ao desenvolvimento de serviços em software de baixo valor agregado. Aqui se encontram, por exemplo, as empresas brasileiras voltadas ao desenvolvimento de software para gestão empresarial, que normalmente evoluíram de serviços especializados para soluções "empacotadas", e que 
hoje estão sofrendo forte e crescente ameaça por parte de empresas transnacionais nos mercados que antes eram relegados às empresas locais (medium e high-end) (Roselino \& Gomes, 2003). A existência dessas empresas nacionais nos segmentos mais competitivos reforça a percepção dos potenciais da indústria brasileira, bem como a pertinência de políticas específicas voltadas ao fortalecimento destas. Conforme se apontará na "análise latitudinal” das Categorias 3 e 4, a maior intensidade da presença de empresas estrangeiras nos segmentos de maior conteúdo tecnológico indica a maior pressão competitiva a que estão sujeitas as empresas nacionais atuantes nestes mercados.

\subsection{Análise longitudinal: as empresas estrangeiras de software}

É significativa a presença de empresas estrangeiras no mercado brasileiro de software. A distribuição dessas empresas pelas categorias consideradas apresenta um quadro com aspectos diferenciados daquele observado para as empresas nacionais privadas (Tabela 6).

O conjunto das empresas estrangeiras era responsável por uma receita operacional líquida total de $\mathrm{R} \$ 3,4$ bilhóes em 2002, o que representa cerca de $33,6 \%$ da receita operacional líquida total da indústria naquele ano, a partir dos critérios aqui adotados. Ainda que isoladamente a categoria de serviços em software de baixo valor seja predominante, com a presença de 47 das empresas estrangeiras atuantes no mercado brasileiro, a soma das outras duas categorias responde pela maioria das empresas e por $61 \%$ da receita operacional líquida total.

Aqui se percebe também, assim como na análise longitudinal das empresas brasileiras privadas, o caráter mais intensivo em mão-de-obra das atividades caracterizadas como sendo de menor valor agregado, uma vez que estas concentram $52 \%$ do pessoal ocupado por empresas estrangeiras, mas são responsáveis por apenas 39\% da receita total. O número de pessoas ocupadas pelas empresas estrangeiras (11.880 pessoas) era menos de uma sexta parte do total empregado pelas empresas brasileiras privadas. As empresas estrangeiras apresentavam claramente uma produtividade bastante superior à das nacionais, o que é indicado pelo valor da receita operacional líquida per capita.

Outro aspecto importante, destacado pelos dados da Tabela 7, é que as maiores empresas estrangeiras presentes no mercado brasileiro são aquelas que 
TABELA 6

Caracterização das empresas estrangeiras de software no mercado brasileiro valores em R\$ milhões (2002)

\begin{tabular}{|c|c|c|c|c|}
\hline & $\begin{array}{c}\text { Serviços em } \\
\text { software } \\
\text { (baixo valor) }\end{array}$ & $\begin{array}{c}\text { Serviços em } \\
\text { software } \\
\text { (alto valor) }\end{array}$ & $\begin{array}{c}\text { Software- } \\
\text { produto }\end{array}$ & $\begin{array}{r}\text { Média } \\
\text { geral }\end{array}$ \\
\hline Número de empresas & 36 & 11 & 29 & 76 \\
\hline$\%$ & $47 \%$ & $14 \%$ & $38 \%$ & $100 \%$ \\
\hline Receita líquida total & 1.349 & 951 & 1.161 & 3.461 \\
\hline$\%$ & $39 \%$ & $27 \%$ & $34 \%$ & $100 \%$ \\
\hline Pessoal ocupado & 6.235 & 2.847 & 2.798 & 11.880 \\
\hline$\%$ & $52 \%$ & $24 \%$ & $24 \%$ & $100 \%$ \\
\hline
\end{tabular}

Fonte: elaboração própria com base nos microdados da PAS e RAIS.

se concentram no segmento de serviços em software de alto valor agregado, apresentando o maior número médio de pessoas ocupadas, assim como um valor de receita operacional líquida média que era mais do que duas vezes superior à das outras categorias.

Percebe-se claramente (assim como na análise longitudinal das empresas nacionais privadas) a maior produtividade relativa das empresas voltadas para os segmentos de software-produto, em que se beneficiam de consideráveis vantagens de escala. Observa-se que a receita operacional líquida obtida pelas empresas de software-produto para cada pessoa ocupada era quase o dobro do valor correspondente para as empresas voltadas a serviços de baixo valor. Parte dessa maior produtividade das empresas estrangeiras se explica certamente pela comercialização no mercado brasileiro de produtos desenvolvidos fora do País, que passariam apenas por processos de tradução e/ou customização para as características da demanda local.

É certo também que a despeito da predominância de empresas nacionais nos valores totais do mercado brasileiro, as empresas estrangeiras apresentam 
TABELA 7

Caracterização das empresas estrangeiras de software valores médios em $R \$$ (2002)

\begin{tabular}{lcccc}
\hline & $\begin{array}{c}\text { Serviços em } \\
\text { software } \\
\text { (baixo valor) }\end{array}$ & $\begin{array}{c}\text { Serviços em } \\
\text { software } \\
\text { (alto valor) }\end{array}$ & $\begin{array}{c}\text { Software- } \\
\text { produto }\end{array}$ & $\begin{array}{r}\text { Média } \\
\text { geral }\end{array}$ \\
Receita líquida média & 37.473 .197 & 86.515 .693 & 40.037 .532 & 45.549 .949 \\
Pessoal ocupado médio & 173 & 259 & 96 & 156 \\
Receita líquida per capita & 216.365 & 334.272 & 414.971 & 291.397 \\
\hline
\end{tabular}

Fonte: elaboração própria com base nos microdados da PAS e RAIS.

individualmente participações relativas significativamente maiores. A receita operacional líquida média das empresas estrangeiras no ano de 2002 era mais de cinco vezes maior que a das empresas nacionais. O segmento em que a desproporção de receita operacional líquida média entre as empresas estrangeiras e nacionais era menor é o de serviços de software de baixo valor, sendo que a receita operacional líquida média das estrangeiras excedia a das nacionais em cerca de 3,5 vezes, contra uma mesma relação de 12,5 vezes no segmento de serviços de alto valor agregado. Curiosamente, no entanto, era este último segmento (serviços de alto valor agregado) que apresentava menor diferença de "eficiência produtiva", com uma receita operacional líquida per capita 3,3 vezes maior para as estrangeiras ( $\mathrm{R} \$ 334.272,00$ contra $\mathrm{R} \$ 102.584,00)$.

\subsection{Análise latitudinal: o segmento de serviços em software de baixo valor agregado}

O segmento de serviços em software de baixo valor agregado é o maior dentre aqueles identificados pela metodologia proposta. O valor da receita operacional líquida das empresas classificadas nesta categoria totalizou mais de $\mathrm{R} \$$ 6,3 bilhões no ano de 2002, o que representava 61\% do valor total do 
TABELA 8

Caracterização do segmento de serviços em software de baixo valor valores em R\$ milhões (2002)

\begin{tabular}{ccccc}
\hline & $\begin{array}{c}\text { Nacionais } \\
\text { privadas }\end{array}$ & $\begin{array}{c}\text { Nacionais } \\
\text { públicas }\end{array}$ & Estrangeiras & Total \\
Número de empresas & 368 & 13 & 36 & 417 \\
$\%$ & $88 \%$ & $3 \%$ & $9 \%$ & $100 \%$ \\
Receita líquida total & 3.800 & 1.180 & 1.349 & 6.330 \\
$\%$ & $60 \%$ & $19 \%$ & $21 \%$ & $100 \%$ \\
Pessoal ocupado & & & & \\
$\%$ & 60.082 & 13.686 & 6.235 & 80.003 \\
& $75 \%$ & $17 \%$ & $8 \%$ & $100 \%$ \\
\hline
\end{tabular}

Fonte: elaboração própria com base nos microdados da PAS e RAIS.

mercado de software naquele ano (Tabela 8). Esse segmento responde também pela maior parte das empresas, com 56\% do total. Em razão do caráter intensivo em trabalho das suas atividades, esse segmento respondia por uma parcela ainda maior do total de pessoas ocupadas, com cerca de $77 \%$ do total da indústria brasileira de software.

O segmento de serviços em software de baixo valor agregado é aquele em que se percebe o maior predomínio das empresas de capital nacional, com a presença de empresas privadas e públicas sendo responsáveis por $79 \%$ da receita operacional líquida total. Parece consistente o fato de que todas as empresas públicas de software ficaram enquadradas nesse segmento, ${ }^{15}$ uma vez que as empresas públicas estão normalmente voltadas ao processamento de informações e manutenção de bancos de dados do setor público.

Conforme já se afirmou, esse segmento é o que envolve menor densidade tecnológica e, por conseqüência, menores barreiras à entrada relacionadas com

\footnotetext{
15 Outras sete empresas classificadas como públicas foram enquadradas como pertencentes à Categoria 1, de "serviços em informática".
} 
o domínio de conteúdos tecnológicos de acesso restrito. Dentre os três segmentos este é, portanto, aquele que em que o custo da mão-de-obra desempenha papel mais importante na determinação da competitividade. Nesse sentido Salatti aponta que:

(...) um fator importante para análise é que o custo só é considerado variávelchave para as empresas com foco em serviço de baixo valor. Para as outras, isso deixa de ser fundamental e outras variáveis, como número de clientes e quotas de mercado ganham importância (2004:32).

Por essa razão, esse segmento parece ter sido aquele que melhor apresentou condiçôes para o florescimento, desenvolvimento e preservação de um grande número de empresas nacionais privadas. A receita operacional líquida média das empresas nacionais privadas desse segmento apresentava menor diferença com relação aos valores apresentados pelas empresas estrangeiras (Tabela 9). Observase também que as empresas nacionais privadas tinham dimensões semelhantes às estrangeiras pelo critério do pessoal ocupado médio, mas apresentavam significativa diferença da receita operacional líquida per capita ( $\$$ \$ 63.263,00 para as nacionais privadas ante $\mathrm{R} \$ 216.365,00$ para as estrangeiras).

\section{TABELA 9}

Caracterização das empresas de serviços em software de baixo valor valores médios em R\$ (2002)

\begin{tabular}{lcccc}
\hline & $\begin{array}{c}\text { Nacionais } \\
\text { privadas }\end{array}$ & $\begin{array}{c}\text { Nacionais } \\
\text { públicas }\end{array}$ & Estrangeiras & Média \\
Receita líquida média & 10.328 .643 & 90.833 .581 & 37.473 .197 & 15.181 .804 \\
Pessoal ocupado médio & 163 & 1.053 & 173 & 192 \\
Receita líquida per capita & 63.263 & & & \\
& & & & \\
\end{tabular}

Fonte: elaboração própria com base nos microdados da PAS e RAIS. 
Essa significativa diferença explica-se possivelmente pelo fato de que as empresas nacionais estão voltadas para clientes menores, que são atraídos pelas vantagens de custo que as empresas nacionais podem oferecer, ao passo que as empresas estrangeiras prestam serviços mais rentáveis para grandes clientes (do sistema financeiro e de seguros, por exemplo) que preferem a estabilidade e maior garantia de continuidade que as empresas globais podem oferecer. Outra possibilidade a se considerar é de que parte das empresas nacionais dessa categoria desempenha funções terceirizadas para as empresas maiores, especialmente estrangeiras, numa prática muitas vezes citada como sendo de "quarteirização". ${ }^{16}$ Assim, teríamos nas diferenças observadas de produtividade do trabalho nas empresas desse mesmo grupo a expressão "quantitativa" de diferentes posições ocupadas pelas empresas nas cadeias produtivas do software.

\subsection{Análise latitudinal: o segmento de serviços em software de alto valor agregado}

A apreciação dos dados do segmento de serviços em software de alto valor oferece um quadro bastante distinto daquele observado no de serviços em software de baixo valor. Nesta categoria estão presentes empresas que desempenham funções abrangem o domínio de conhecimentos específicos das etapas próprias à engenharia de software, necessárias para a elaboração da análise de requisitos e design de alto nível. Assim, as atividades compreendidas por essa categoria freqüentemente exigem das empresas um maior empenho no desenvolvimento de funções corporativas mais complexas, como esforços formais de P\&D e estratégias mais dispendiosas em marketing.

De forma geral, a pressão competitiva nessa categoria impõe a necessidade de estruturas organizacionais mais eficientes, com a adoção de metodologias e processos de desenvolvimento mais maduros, com procedimentos internos voltados ao atendimento de especificaçôes e métricas de qualidade. No caso de projetos mais complexos, que envolvem funções críticas das empresas contratantes,

\footnotetext{
16 Dados preliminares de pesquisa em desenvolvimento pelo "Observatório Digital Softex" intitulada "Indústria Brasileira de Software e Novas Modalidades de Outsourcing" apontavam para a constatação destas práticas, segundo a matéria "Parcerias têm espaço certo", publicada na Gazeta Mercantil (Caderno C - p. 1, Roberta Prescott/IT Mídia$\mathrm{TI}, 15 / 12 / 2005)$.
} 
a reputação da empresa desenvolvedora ganha muito peso quando se trata de serviço de elevado valor agregado, pois a empresa-cliente investe muito tempo e valores significativos num projeto em parceria com a desenvolvedora. Como tempo e dinheiro são fundamentais, o investimento acontece quando o nome da empresa a ser contratada tem uma boa reputação no mercado (Salatti, 2004:32).

Assim, diferentemente da dinâmica competitiva existente no segmento de serviços em software de baixo valor, aqui as barreiras à entrada já operam com intensidade. Se no caso anterior o custo de desenvolvimento (determinado primariamente pelo custo da mão-de-obra) é a variável-chave, aqui fatores como o domínio de conhecimentos específicos a cada nicho ganha relevância. A maior complexidade das atividades envolvidas exige estreita interação entre as empresas desenvolvedoras e demandantes.

A necessidade de diálogo traz então exigências que tornam a compra mais complexa, fugindo do conceito de "commodity" e introduzindo fatores mais subjetivos. Quanto mais subirmos na cadeia de valor, mais será importante o conhecimento do negócio. Enquanto a mera codificação pode ser feita sem que o programador tenha a menor idéia de onde ela vai se encaixar. Aqui há necessidade de uma "cultura de entendimento" (Saur, 2004:50).

Ademais, nesse segmento já se identifica o recurso crescente de práticas voltadas à captura de ganhos de escala, como a aplicação das técnicas de componentização e crescente reuso de módulos.

Os dados da Tabela 10 indicam que as atividades desse segmento envolveram valores próximos a $\mathrm{R} \$ 2$ bilhões em receita operacional líquida para o ano de 2002. Esse montante representou $14,1 \%$ da receita operacional líquida total da indústria de software para aquele ano, segundo os critérios aqui empregados.

Aqui se percebe que, a despeito do número de empresas nacionais representar cerca de $93 \%$ do total do segmento, ocorria um equilíbrio na distribuição da receita operacional líquida total por origem do capital das empresas. Onze empresas estrangeiras respondiam por praticamente metade da receita operacional líquida total apurada para o segmento. 
TABELA 10

Caracterização do segmento de serviços em software de alto valor valores em $R \$$ milhões (2002)

\begin{tabular}{cccc}
\hline & $\begin{array}{c}\text { Nacionais } \\
\text { privadas }\end{array}$ & Estrangeiras & Total \\
Número de empresas & 140 & 11 & 151 \\
$\%$ & $93 \%$ & $7 \%$ & $100 \%$ \\
Receita líquida total & 968.089 & 951.672 & 1.919 \\
$\%$ & $50 \%$ & $50 \%$ & $100 \%$ \\
Pessoal ocupado & & & 12.284 \\
$\%$ & 9.437 & 2.847 & $100 \%$ \\
\hline
\end{tabular}

Fonte: elaboração própria com base nos microdados da PAS e RAIS.

Outro elemento que sobressai na leitura dos dados é tamanho significativamente maior das empresas transnacionais pelo critério do número médio de pessoas ocupadas, revelando um quadro diverso daquele observado para serviços de baixo valor (Tabela 11).

O maior market-share ${ }^{17}$ das empresas estrangeiras nesse segmento, relativamente ao de serviços em software de baixo valor, aponta para maiores vantagens competitivas dessas empresas globais, apoiadas em condições mais favoráveis relativas aos elementos determinantes da competitividade para esse segmento. É bastante provável que as empresas estrangeiras prestadoras desses serviços estejam atuando no mercado brasileiro como parte de redes de fornecimentos estabelecidas globalmente. Ou seja, estas empresas replicariam no mercado brasileiro relações de fornecimento de serviços para empresas globais dos mais diversos setores, reproduzindo neste mercado vínculos estabelecidos globalmente.

Em um raciocínio análogo, sugere-se que parte significativa das empresas

\footnotetext{
17 Cada empresa estrangeira tem em média pouco menos do que $5 \%$ do mercado desse segmento, se tomarmos por base a participação da receita operacional líquida média sobre o valor total.
} 
TABELA 11

Caracterização das empresas de serviços em software de alto valor valores médios em R\$ (2002)

Nacionais

privadas

Receita líquida média

Pessoal ocupado médio

Receita líquida per capita
Estrangeiras

Média

Fonte: elaboração própria com base nos microdados da PAS e RAIS.

nacionais atuantes nesse segmento esteja vinculada a grupos e empresas com as quais estabeleceram relações de fornecimento desde a fundação. Muitas empresas atuantes no atendimento de serviços bancários originaram-se de grandes bancos nacionais e preservam com estes estreitos laços estratégicos e comerciais, por exemplo.

Apoiadas em marcas globalmente reconhecidas, posiçôes consolidadas como fornecedoras de soluções para grandes clientes globais, assim como maiores possibilidades de ganhos de escala, as empresas estrangeiras apresentaram uma receita operacional líquida per capita média cerca de três vezes superior à das nacionais. Cabe reafirmar, no entanto, que dentre os três segmentos este é que apresenta menor desproporção relativa neste aspecto.

De forma geral os números comprovam a maior rentabilidade das atividades desenvolvidas pelas empresas (nacionais ou estrangeiras) nessa categoria com relação às classificadas como sendo voltadas aos serviços de baixo valor agregado, tomando-se como referência a receita operacional líquida per capita. As empresas nacionais apresentaram um valor $62,2 \%(\mathrm{R} \$ 102.584$ contra $\mathrm{R} \$ 63.263)$ maior para este indicador, ao passo que no caso das empresas estrangeiras a diferença 
positiva foi de $54,2 \%$ ( $\$ 334.272$ contra $R \$ 216.365$ ), confirmando as características diferenciadas entre estes dois segmentos, conforme os elementos desenvolvidos.

\subsection{Análise latitudinal: o segmento de software-produto}

O segmento de software-produto é aquele em que com maior intensidade se identificam barreiras à entrada associadas às vantagens de escala, garantindo elevadas vantagens competitivas para empresas com mais amplas bases de clientes. Esse fator que opera no sentido da concentração do mercado é ainda intensificado em alguns casos específicos em que o produto se destina aos mercados horizontais. Nesse caso as externalidades associadas às economias de rede garantem elevado poder de mercado para firmas que lograram a imposição de padrões tecnológicos dominantes.

Estes fatores resultam em um efeito de "trancamento" (lock-in) do mercado por parte de empresas que conquistaram grandes fatias de mercado em razão do tempo (timing) de entrada no mercado. Em segmentos de softwarepacote de uso horizontal posições monopolistas de facto foram estabelecidas globalmente desde os primórdios desta indústria, especialmente por empresas estadunidenses. Esse processo de concentração deu-se não apenas nos softwares de uso mais geral (como aqueles em que se dá o monopólio da Microsoft), mas também se apresenta, com maior ou menor intensidade, para ferramentas de desenvolvimento, linguagens de programação e software para o gerenciamento de banco de dados, por exemplo. É, por isso, bastante plausível que a participação de empresas estrangeiras seja maior neste segmento não apenas no Brasil, mas certamente também nos mais diversos mercados nacionais, com a exceção evidente do mercado estadunidense.

Essas considerações explicam o fato de que dentre os três segmentos estudados o de software-produto é o único em que se verifica o predomínio de empresas estrangeiras na origem da receita operacional líquida total. As empresas estrangeiras que representam cerca de $16 \%$ do universo total presente nesse segmento respondem por uma parte majoritária (56\%) da receita operacional líquida total (Tabela 12). Ainda assim, é bastante significativa a participação de conjunto das empresas nacionais na composição de receita operacional líquida 
TABELA 12

Caracterização do segmento de software-produto

Valores em R\$ milhões (2002)

\begin{tabular}{cccc}
\hline & $\begin{array}{c}\text { Nacionais } \\
\text { privadas }\end{array}$ & Estrangeiras & Total \\
Número de empresas & 149 & 29 & 178 \\
$\%$ & $84 \%$ & $16 \%$ & $100 \%$ \\
Receita líquida total & 894.349 & 1.161 .088 & 2.055 .437 \\
$\%$ & $44 \%$ & $56 \%$ & $100 \%$ \\
Pessoal ocupado & 8.274 & & 11.072 \\
$\%$ & $75 \%$ & 2.798 & $100 \%$ \\
\hline
\end{tabular}

Fonte: elaboração própria com base nos microdados da PAS e RAIS.

total do segmento, considerando-se que estão aqui presentes empresas que possuem posiçôes monopolistas globalmente consolidadas.

Deve-se ter em consideração a existência de mercados do segmento de software-produto, especialmente no caso de soluções voltadas aos mercados verticais, em que as empresas estrangeiras atuam como concorrentes diretas das empresas nacionais, num ambiente que é crescentemente competitivo. ${ }^{18}$ A observação dos valores médios relativos às empresas nacionais e estrangeiras nesse segmento revela também aspectos significativos (Tabela 13). Percebe-se que a média da receita operacional líquida do segmento é 134,6\% superior ao mesmo indicador verificado no segmento de serviços de baixo valor agregado, e ainda $18,8 \%$ superior ao do segmento de alto valor agregado. Esses números refletem as distintas características que definem o "modelo de negócio" do software nos segmentos identificados, como o papel desempenhado pelos ganhos crescentes de escala nos segmentos de serviços de alto valor, e sua maior expressão no segmento de software-produto.

\footnotetext{
${ }^{18}$ Este é o caso do mercado de software integrado de gestão (ERP), em que as grandes empresas estrangeiras, após a saturação do mercado dos segmentos high-end, voltam-se atualmente também para os mercados medium-end e mesmo low-end, tradicionalmente ocupados por empresas nacionais (Gutierrez \& Alexandre, 2005).
} 


\begin{tabular}{lccc}
\hline & $\begin{array}{c}\text { Nacionais } \\
\text { privadas }\end{array}$ & Estrangeiras & Média \\
Receita líquida média & 6.002 .344 & 40.037 .532 & 11.547 .403 \\
Pessoal ocupado médio & 56 & 96 & 62 \\
Receita líquida per capita & 108.092 & 414.971 & 185.643 \\
\hline
\end{tabular}

Fonte: elaboração própria com base nos microdados da PAS e RAIS.

Percebe-se, no entanto, que no caso das empresas nacionais esses ganhos são menos significativos, resultando em uma receita operacional líquida per capita 70,9\% superior às empresas nacionais atuantes no segmento de serviços de baixo valor, e apenas ligeiramente maior que a verificada no segmento de serviços de alto valor (5,4\% superior). A menor vantagem obtida por ganhos de escala das empresas nacionais de software-produto vis-à-vis às empresas estrangeiras deve-se certamente à maior fragmentação dos mercados em que atuam as empresas nacionais, ao passo que as estrangeiras obtêm vantagens elevadas com a comercialização de produtos comercializados em escala global. A fragmentação dos mercados de software-pacote em que atuam as empresas nacionais, e essas decorrentes menores vantagens de escala são certamente os mais importantes pontos de fragilidade da indústria nacional de software, uma vez que parte significativa dessas empresas está exposta a um ambiente fortemente competitivo em mercados em que empresas estrangeiras estão presentes. Conforme Menezes et al::

Essa peculiaridade quanto ao fato das empresas nacionais serem pequenas e numerosas, contrariando a tendência internacional de crescente concentração, decorre de uma excessiva replicação de produtos em diferentes mercados locais ou regionais (2005:34). 
Parte significativa das empresas nacionais do segmento de software-produto se originou e cresceu apoiada no atendimento a empresas locais, sendo que algumas se formaram a partir do spin-off de empresas dos mais diversos setores, e continuam vinculadas ao atendimento de um restrito mercado regional. Essa fragmentação da oferta, provenientes de empresas nacionais com produtos análogos, resulta numa dispersão de esforços tecnológicos e mercadológicos, na medida em que se baseia no desenvolvimento de soluções redundantes. ${ }^{19}$ Num segmento em que as vantagens relativas à diluição dos custos de desenvolvimento em uma grande base de clientes tem papel crítico, este quadro parece pesar como um fator de desvantagem para as empresas nacionais.

O quadro sugere a necessidade de uma maior consolidação em alguns mercados, com a formação de joint ventures, assim como operações de fusões e aquisiçôes, com o objetivo de se criar condições para um enfrentamento menos desproporcional entre grandes fornecedores globais e empresas nacionais de software-produto. Conclui-se que este elemento de fragilidade parece recomendar a formulação de políticas específicas voltadas à sua superação. Conforme se, a atual proposta de política industrial, com especial destaque para a atuação do Prosoft-BNDES parece ser um instrumento adequado para promover a indústria nacional especialmente nesse segmento de software-pacote. A existência de linhas de financiamento adequadas às características (patrimoniais inclusive) das empresas de software pode proporcionar o fortalecimento das empresas nacionais na competição com empresas estrangeiras.

As medidas adotadas devem privilegiar ações que promovam vantagens associadas aos ganhos de escala, ampliando a base de clientes. Para isso o instrumento específico do Prosoft-Comercialização, assim como a atuação do BNDES em operações de fusóes e aquisições se mostram adequada.

Apresentam-se a seguir algumas observaçóes sobre o desempenho exportador da indústria brasileira de software, baseados em dados consolidados segundo a tipologia empregada nesse trabalho.

\footnotetext{
19 É o caso de empresas que nasceram originalmente de atividades de software desenvolvidas in-house nas sedes de grupos industriais ou de instituições financeiras, por exemplo. Esse quadro explica a existência de importantes empresas nacionais com produtos similares localizadas nos maiores centros econômicos do País: São Paulo, Rio de Janeiro e Belo Horizonte.
} 


\subsection{Desempenho exportador da indústria brasileira de software}

O desempenho exportador da indústria brasileira de software é um dos aspectos mais desafiadores para aqueles que se empenham na análise do setor. Sob qualquer perspectiva os números conhecidos são desproporcionalmente acanhados frente aos valores gerais movimentados por esta indústria, especialmente quando se contrastam com os valores de outros países não-centrais com indústrias de software de proporções semelhantes.

Durante um considerável período divulgou-se que o valor total das exportações brasileiras de software totalizava US\$100 milhōes. Esse "número padrão" foi reproduzido em uma grande variedade de publicações, e por seguidos anos. $\mathrm{O}$ valor teria sido produzido pelo SOFTEX por meio de estimativas amparadas em levantamentos amostrais direcionados. Melo \& Castello Branco (1997) já apontavam este valor como sendo relativo às exportaçôes de software referentes ao ano de 1995. Posteriormente o mesmo valor seria apresentado em estudos mais recentes, como no relatório final de uma pesquisa desenvolvida em 2003 (Veloso et al., 2003), que aponta os mesmos US\$ 100 milhões como sendo o montante de software brasileiro exportado no ano de 2000.

O fato é que inexiste na literatura qualquer indicador confiável de comercialização da indústria brasileira de software brasileiro no exterior, com referências consistentes e claras com relação à metodologia de coleta das informações apresentadas. As razões para essa deficiência a respeito de dados sobre a comercialização de software no exterior já foram expostas neste trabalho. Os problemas principais envolvendo estas estatísticas para o caso brasileiro foram claramente apresentados por Stefanuto e Carvalho:

a exportação de software pode ser invisivel, ou seja, é fácil escapar ao registro a comercialização com o exterior de um software ou de um serviço correlato. Isso se deve ao fato de que software e serviços correlatos são intangiveis, podendo ser disponibilizados remotamente via Internet para qualquer lugar do mundo. Desta forma, são necessários instrumentos de registro, regulação e classificação para as atividades de software capazes de captar suas peculiaridades, que diferem substancialmente dos setores tradicionais da induistria. No Brasil, o que observamos é desorganização e ausência de informaçōes referentes ao setor, devido à falta de adequação desses instrumentos (2005:42). 
Os números existentes na literatura foram elaborados geralmente a partir de estimativas realizadas com base em informações amostrais, colhidas de empresas selecionadas a partir de notícias divulgadas na imprensa especializada, como "casos de sucesso da exportação de software". Esse procedimento metodológico apresenta evidentes fragilidades, especialmente relacionadas à representatividade da amostra coletada, como no caso dos dados apresentados em Ferraz Filho et al. (1998). ${ }^{20}$

No mais recente estudo do desempenho exportador de software existente para o caso brasileiro (Stefanto \& Carvalho, 2005) o valor estimado para o ano de 2004 (US\$ 314 milhôes) foi obtido a partir de uma amostra de 30 empresas (nacionais e estrangeiras), aparentemente incluindo-se também dados de exportações de empresas estrangeiras de equipamentos de informática e tele-equipamentos. A valor apurado para as exportaçōes das empresas nacionais foi obtido a partir de uma "hipótese heróica" definida ad hoc:

Uma maneira de aperfeiçoar os indicadores obtidos nesta pesquisa, de forma a contrabalançar a tendência à subdeclaração das empresas nacionais, é estimar um percentual médio de valor exportado em relação à receita total de vendas de software e serviços correlatos das empresas da amostra. Nesse sentido, definiu-se aqui como estimativa (valor potencialmente exportado) o valor de $15 \%$ da receita total da comercialização de software [grifo $\mathrm{meu}$. Esse percentual foi adotado a partir de informaçôes sobre exportaçôes de software declaradas por empresas que se destacam individualmente como exportadoras e têm sido registradas na imprensa. Considerando que as receitas de comercialização de software e serviços correlatos das empresas nacionais da amostra foram de US\$1.007,5 milhão, em 2004, a adoção do percentual de 15\% leva à estimativa de US\$151 milhöes de valor exportado por esse grupo (Stefanuto \& Carvalho, 2005:11).

A utilização desse recurso metodológico pouco convencional de mensuração sugere a dificuldade dos autores do referido trabalho em encontrar valores efetivamente declarados de comercialização de software no exterior por parte das empresas entrevistadas, comprometendo a representatividade do valor obtido.

\footnotetext{
20 Desenvolvido a partir de pesquisa que contou com a participação do autor do presente trabalho.
} 
Independentemente da metodologia adotada para a aferição do desempenho exportador da indústria brasileira de software, o resultado aparece como desproporcionalmente pequeno com relação às dimensôes gerais da atividade doméstica, especialmente quando contrastados com os valores advindos de indústrias de proporções semelhantes situadas em países não-centrais (como nos casos já citados de Índia, Irlanda, Israel, e mesmo China).

As justificativas apontadas na literatura para o fraco desempenho exportador vão desde determinantes macroeconômicos, como os efeitos da valorização cambial promovida no período de implantação do Plano Real (Rocha, 1998), passando pela ausência de uma "cultura exportadora", assim como em um "viés antiexportação" determinado estruturalmente pela existência de um vasto mercado interno (Veloso et al., 2003).

É certo que o fraco desempenho exportador se explica a partir de uma complexa conjunção de fatores, sem que se possa apontar um único determinante explicativo como central ou mais importante. A apreciação cambial poderia explicar uma conjuntura pouco propícia para as atividades voltadas à exportação de software, mas é certamente um fator pouco relevante para explicar uma característica que se apresenta como estrutural. Também a explicação baseada na significativa dimensão do mercado doméstico parece ser insuficiente. Um grande mercado interno, dotado de complexidade e sofisticação de sua deman$\mathrm{da}$, representa potencialmente um fator mais propriamente estimulante da competitividade da indústria nacional, do que um elemento de entrave ao sucesso no mercado externo.

Esse argumento seria sustentável apenas numa situação em que o mercado doméstico apresentasse um ambiente com baixa pressão competitiva, propiciando uma cômoda situação de alta rentabilidade para as empresas nacionais. Os dados apresentados, assim como a literatura especializada, apontam para uma configuração diversa. A existência de empresas estrangeiras (ainda que com intensidade diferenciada) em todas categorias, assim como os indicadores de produtividade relativa indicam um quadro de fortes pressões competitivas, especialmente nos segmentos mais dinâmicos de serviços em software de alto valor e software-produto.

As reflexões deste trabalho com relação ao desempenho exportador da indústria brasileira de software serão desenvolvidas com base em dados obtidos 
censitariamente do universo de empresas de software com mais de 20 empregados atuantes no mercado brasileiro no ano 2002.

Vale ressaltar que os valores das exportações de software que se apresentam aqui são relativos à indústria brasileira de software, no sentido adotado neste trabalho: o conjunto de empresas que tem em atividades voltadas ao software sua principal fonte de receita. Assim, os valores que se apresentam a seguir são certamente muito inferiores ao total de exportaçōes de software, que englobariam todo tipo de software (incluindo-se o software embarcado) exportado a partir de empresas pertencentes a outras indústrias (especialmente as de equipamentos de informática, tele-equipamentos e eletrônica de consumo).

Os procedimentos metodológicos adotados possibilitaram a análise do desempenho da indústria brasileira de software no mercado externo para cada segmento da tipologia construída, permitindo um panorama diferenciado dos resultados obtidos no mercado externo para o ano de 2002 (Tabela 14) ${ }^{21}$

O valor total obtido no exterior pelas empresas de software e serviços de informática foi de $\mathrm{R} \$ 290$ milhóes em 2002,22 sendo que deste total 82,5\% advieram de empresas classificadas com sendo parte da indústria brasileira de software (excluindo-se as empresas da Categoria 1). Pode-se afirmar assim que a indústria brasileira de software obteve uma receita de $\mathrm{R} \$ 239,3$ milhões (ou US\$ 81,6 milhões) ${ }^{23}$ com exportações no ano de 2002. ${ }^{24}$

No entanto, é marcante o fato de que este valor foi quase inteiramente gerado a partir da operação de empresas estrangeiras no Brasil. São as empresas estrangeiras voltadas ao desenvolvimento de serviços de alto valor agregado (com $50 \%$ ), e estrangeiras voltadas a software-produto (com 41,6\%) as responsáveis pela quase totalidade da receita externa aferida.

\footnotetext{
21 O questionário suplementar para as empresas de "serviços de informática" trouxe pela primeira vez no ano de 2002, um campo destinado à declaração da porcentagem da "receita obtida no exterior", discriminada entre receita obtida com "serviços" ou "mercadorias".

${ }^{22}$ Este valor refere-se às empresas que formam a base de dados depurada e que foram classificadas pela tipologia acima.

${ }^{23}$ Convertido pela taxa de câmbio média no ano, de R\$2,9309/1US\$.

${ }^{24}$ Considerando-se os mais diversos canais de comercialização do soffware no exterior, a mensuração das "exportações" neste sentido mais abrangente como "Participação da Receita Obtida no Mercado Externo" é certamente a melhor abordagem. A utilização desta base de dados oficial do IBGE tem ainda a vantagem desta ser obtida mediante a garantia de sigilo dos microdados, assim como o fato de ser "politicamente neutra", ou seja, não há no preenchimento deste questionário motivos aparentes para que estas se sintam inclinadas a "inflar" ou "subestimar" os valores efetivamente obtidos.
} 
TABELA 14

Desempenho exportador da indústria brasileira de software e serviços de informática (receita total obtida no exterior em R\$ - 2002)

\begin{tabular}{|c|c|c|c|c|c|c|}
\hline & & Serviços & Produtos & Total & $\%$ & $\% *$ \\
\hline \multirow{3}{*}{$\begin{array}{l}\text { Categoria } 1 \\
\text { Serviços de } \\
\text { informática }\end{array}$} & Nacionais privadas & 2.041 .358 & 6.597 .032 & 8.638 .389 & $3 \%$ & - \\
\hline & Estrangeiras & n.c. & 31.627 .922 & 31.627 .922 & $11 \%$ & - \\
\hline & Nacionais públicas & n.c. & n.c. & 0 & - & - \\
\hline \multirow{3}{*}{$\begin{array}{l}\text { Categoria } 2 \\
\text { Serviços em } \\
\text { software } \\
\text { (baixo valor) }\end{array}$} & Nacionais privadas & n.c. & 4.212 .373 & 4.212 .373 & $1 \%$ & $1,76 \%$ \\
\hline & Estrangeiras & n.c. & 10.454 .714 & 10.454 .714 & $4 \%$ & $4,37 \%$ \\
\hline & Nacionais públicas & n.c. & n.c. & n.c. & - & - \\
\hline
\end{tabular}

Categoria 3

Serviços em software (alto valor)
Nacionais privadas

Estrangeiras

2.733 .938

32.358 .055

4.046 .150

6.780 .088

$2 \%$

$2,83 \%$

90.863 .416

123.221 .471

$42 \% \quad 51,50 \%$
Categoria 4 Nacionais privadas softwareproduto

Estrangeiras n.c.

5.473 .840

19.156

99.577 .514

19.156

$0 \%$

$0,01 \%$

105.051 .35

$36 \%$

$43,90 \%$

Total geral

Total

40.565 .833

Fonte: elaboração própria com base nos microdados da PAS e RAIS.

* Dados das empresas classificadas como sendo parte da indústria brasileira de software (excluindo-se os dados da Categoria 1). 
Outro aspecto que se revela a partir dos dados é o insignificante peso das empresas voltadas aos serviços em software de baixo valor agregado na composição das receitas externas. Isso possivelmente se explica pela inexistência de vantagens comparativas apoiadas em custos salariais, que embora sejam menores que os praticados em países centrais, são substancialmente mais elevados do que os chineses e também os indianos. A maior parte das exportações é oriunda as empresas voltadas ao desenvolvimento de software-produto e serviços de alto valor, indicando uma perspectiva de inserção internacional baseada nesses segmentos. Esse aspecto parece indicar a pertinência de iniciativas voltadas à inserção de software em estratos mais elevados da cadeia de valor, como sugere Saur (2005).

Os dados também sugerem que a maior parte das receitas advém da comercialização de produtos (reportado como mais de $83 \%$ do total) com uma clara predominância destes com relação ao valor comercializado em serviços. Por sua vez, os acanhados $\mathrm{R}$ \$ 11 milhões obtidos a partir das empresas nacionais são particularmente frustrantes se considerarmos a existência de um programa nacional de exportação de software criado há mais de uma década, que se mostrou, a despeito da sua importante atuação em vários aspectos, incapaz de produzir resultados na direção da sua meta inicial, e motivação primeira.

A inexistência dessas informações nas edições anteriores da Pesquisa Anual de Serviços (PAS/IBGE) impede uma leitura temporal "para trás" destes dados, com o intuito de se identificar a existência de algum comportamento tendencial com relação a esses números. No entanto, os valores agregados para a edição seguinte (2003) da Pesquisa Anual de Serviços (PAS) já apontam para um salto significativo dos valores comercializados. O valor total de comercialização da divisão 72 (que compreende as empresas de software e serviços de informática) alcançou a marca de $\mathrm{R} \$ 840$ milhões (ou cerca de US\$ 273,5 milhões), ${ }^{25}$ que representa um crescimento de $225 \%$ com relação ao mesmo valor para o ano analisado de $2002 .{ }^{26}$

\footnotetext{
25 Convertido pela taxa de câmbio média no ano, de R\$3,0715 / 1US\$.

${ }^{26}$ As planilhas com os valores agregados foram apresentados no sítio do IBGE em dezembro de 2005, sendo que, lastimavelmente, até o encerramento deste trabalho os microdados não estavam ainda disponíveis para consulta. No entanto, uma alteração do instrumento de coleta dos dados deve resultar em alguma dificuldade para a análise comparativa dos dois anos. No questionário de 2002 (suplemento para empresas de serviços de informática) as empresas gozavam de liberdade para atribuir suas receitas externas aos campos de "serviços" ou "mercadorias", já o questionário de 2003 (para todas as empresas) induz, através do texto das instruções de preenchimento, a empresa pesquisada a atribuir toda a receita com software ("produto" ou "serviço") como "receita com serviços".
} 


\section{Conclusão}

A constituição da indústria brasileira de software resulta de uma trajetória histórica particular e sua atual conformação reflete potencialidades e restrições que são próprias do modelo brasileiro de desenvolvimento econômico. A configuração dessa indústria é simultaneamente herdeira e parte constituinte de uma estrutura produtiva marcada por restrições, mas também pela conquista de avanços em várias frentes.

Avanços conquistados nesse esforço histórico, voltado ao desenvolvimento tecnológico nacional, resultaram em competências conquistadas em alguns segmentos intensamente dinâmicos como telecomunicações e indústria aeronáutica, por exemplo. Essas competências não residem apenas no segmento diretamente produtivo, mas estão acasteladas, se renovam e se multiplicam a partir de universidades e centros de pesquisa em diversas áreas intensamente tecnológicas. Algumas das maiores empresas de software nasceram a partir de idéias originadas no ambiente acadêmico (como é o caso da Microsiga, formada por dois engenheiros oriundos da Universidade de São Paulo - USP).

Mas não são apenas as iniciativas voltadas às atividades mais intensamente tecnológicas que promoveram um ambiente propício para o desenvolvimento da indústria brasileira de software. Setores produtivos tradicionais, articulados em uma estrutura heterogênea e complexa, também desempenharam papel relevante para o estabelecimento e desenvolvimento de empresas nacionais de software. Muitas das maiores empresas nacionais que hoje operam no mercado de software de gestão empresarial, por exemplo, surgiram vinculadas às atividades dos "centros de processamento de dados" de empresas comerciais e/ou industriais. Algumas se formaram desenvolvendo atividades voltadas aos "centros de processamento de dados" (como é o caso da empresa Datasul) e outras como spin-off desses centros (como é o caso da Logocenter, ${ }^{27}$ que se originou das atividades de uma empresa catarinense de fundição).

A indústria brasileira de software desenvolveu-se apoiada no atendimento de um vigoroso e complexo sistema produtivo, ao qual preserva-se ainda organicamente vinculada. O perfil da indústria brasileira é particular, como a própria trajetória de desenvolvimento industrial do País. Em diversos aspectos essa

\footnotetext{
27 Informações sobre a origem das três empresas citadas (Microsiga, Logocenter e Datasul) foram obtidas em entrevistas no âmbito do projeto Diretório de Pesquisa Privada GEEIN/FINEP.
} 
indústria destaca-se positivamente. A significativa presença de empresas brasileiras, mesmo nas categorias mais dinâmicas, provendo soluções em serviços de alto valor, assim como desenvolvendo e comercializando software-produto para o mercado doméstico indicam a existência de um considerável conjunto de atividades desta indústria sendo conduzida por empresas nacionais.

O que se afirma neste trabalho é que a ênfase nos objetivos de exportação de software deveria dar lugar a uma percepção mais cuidadosa do papel a ser desempenhado pela indústria brasileira de software no mercado doméstico. A política setorial deveria se voltar com mais atenção para os potenciais efeitos transformadores do desenvolvimento e aplicação do software aos problemas brasileiros, nas esferas pública e privada, como fator promotor do desenvolvimento econômico e social da Nação.

Diferentemente do que usualmente se difunde, a empresa nacional ocupa espaço relevante no mercado nacional. A análise apresentada neste trabalho permite mensurar a participação relativa das empresas nacionais e estrangeiras de acordo com os distintos segmentos apresentados. A abordagem apresentada permite perceber um padrão no que se refere a esse aspecto, conforme sintetizado no Gráfico 1.

A participação do software nacional é largamente predominante nos mercados em que atuam as empresas classificadas como voltadas aos serviços em software de baixo valor, caracterizado por baixa intensidade tecnológica, reduzidos ganhos de escala e externalidades de rede limitadas. As empresas classificadas nessa categoria (tanto nacionais quanto estrangeiras) apresentam valores significativamente inferiores de receita líquida per capita. Outro aspecto da estrutura de mercado identificada que corrobora os argumentos construídos é que nesse segmento é que se encontram as menores assimetrias entre empresas nacionais e privadas.

A despeito dessas atividades de baixo valor concentrarem a maior parte das empresas nacionais privadas, chama atenção a significativa participação dessas também nos segmentos de serviços em software de alto valor agregado e de softwareproduto. No caso do segmento de serviços em alto valor se observa uma participação equilibrada entre as empresas nacionais e estrangeiras na composição da receita operacional. Esse tipo de atividade já envolve as etapas mais complexas do processo produtivo, incluindo-se as funções relativas à engenharia de software (design de alto nível e análise de sistemas, por exemplo). 
GRÁFICO 1

Participação das empresas nacionais e estrangeiras no mercado nacional

(porcentagem da receita operacional líquida total - 2002)

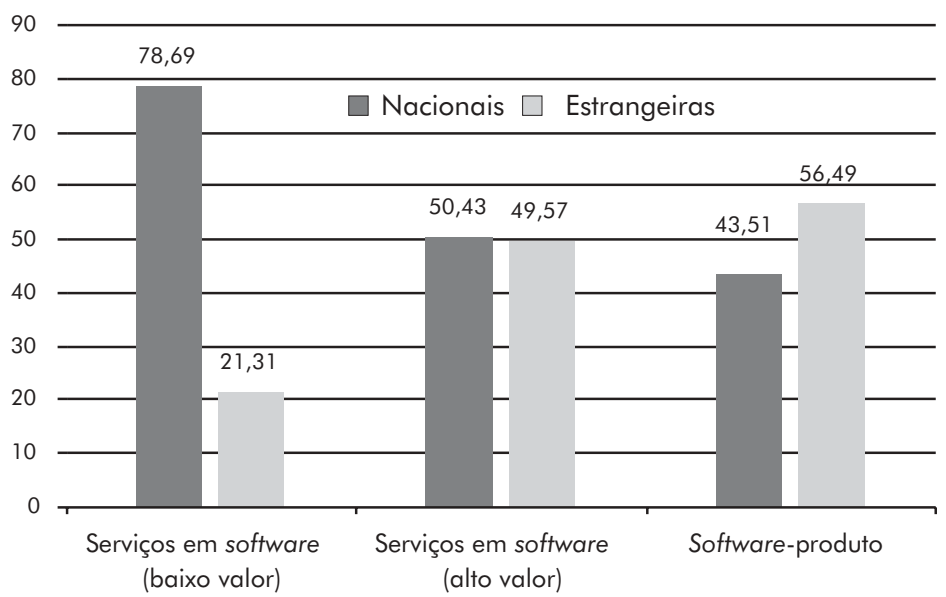

Fonte: elaboração própria com base nos microdados da PAS e RAIS.

Dentre as três categorias da taxonomia proposta, a única em que se configura um predomínio da empresa estrangeira é no segmento de software-produto. Ainda assim, a presença das empresas nacionais é bastante expressiva, indicando um considerável número de empreendimentos de origem nacional no segmento em que se verifica com maior intensidade a existência de barreiras à entrada, apoiadas normalmente em expressivos retornos crescentes de escala, que conferem às grandes empresas estrangeiras substantivas vantagens competitivas.

As políticas públicas voltadas à consolidação da parte nacional da indústria brasileira de software deveriam estar centradas na superação daquela que parece ser sua maior fragilidade: o reduzido porte médio das empresas, aspecto especialmente crucial na determinação das possibilidades de competição com as empresas estrangeiras nos segmentos mais produtivos e tecnologicamente complexos (Categorias 3 e 4).

Nesse aspecto, iniciativas desenvolvidas no âmbito da nova política industrial, com especial destaque para a atuação do BNDES são louváveis. O oferecimento de condiçôes mais adequadas de crédito, inclusive para o financiamento do comprador, é um importante instrumento para a promoção das operações das 
empresas nacionais e expansão da base de clientes, inclusive com a exploração de mercados externos em alguns casos.

Complementarmente, deve-se estimular a realização de fusões e aquisições de empresas nacionais para a constituição de empresas com maior "musculatura" nos segmentos em que a concorrência com as empresas estrangeiras se faz mais acirrada (como parece ser o caso de software voltado à gestão empresarial). A existência de uma estrutura fragmentada de oferta de software nacional precisa dar lugar à existência de grupos nacionais consolidados em empresas maiores.

Ressalta-se também que a elevada intensidade das fusões e aquisições caracterizam a dinâmica internacional dessa atividade, não apenas como recurso voltado à ampliação de market-share e decorrentes vantagens de escala, mas também como parte de estratégias inovativas e de imposição (ou preservação) de padrões tecnológicos. Empresas de software adquirem não apenas empresas concorrentes (integração horizontal), mas também empresas com ativos complementares (integração vertical) que resultam em novos módulos ou funções adicionais em soluçôes de software, em outras palavras, inovação. Esse caráter inovativo que assumem muitas operações de F\&A precisa ser levado em conta, pautando a atuação não apenas do BNDES, mas também da FINEP.

Os objetivos expressos na PITCE voltados à difusão e democratização das tecnologias de informática para as classes populares e micro e pequenas empresas são também acertadas, não apenas pelas possibilidades abertas pela "inclusão digital" e pelos potenciais ganhos de eficiência dos empreendimentos atendidos, mas também pela oportunidade de se incorporar o setor nacional privado nesses esforços. O direcionamento de parte do poder de compra do Estado para empresas que possam ser engajadas nesses projetos seria bastante oportuno para o fortalecimento de empresas nacionais.

Este trabalho defende a coordenação das políticas públicas voltadas ao software, tendo como meta o fortalecimento da empresa nacional e a potencialização dos efeitos dinamizadores do software sobre a estrutura produtiva brasileira e outras atividades que visem maior bem-estar social, inclusive no desempenho das funções do Estado. Isso não significa abandonar, nem mesmo atribuir pouca importância aos objetivos de comercialização no exterior, mas compreender que uma inserção externa mais virtuosa, participando em funções mais complexas na divisão internacional do trabalho, só será alcançada a partir de uma sólida base nacional. 


\section{Referências bibliográficas}

Arbache, J., Análise do Setor de Software Brasileiro, Ministério do Desenvolvimento Indústria e Comércio Exterior, e Depto. de Economia da Universidade Nacional de Brasília, 2002.

Carvalho Jr., A.M., "A Política Industrial e o BNDES", Revista do BNDES, v.12, n.23, p.17-28, jun., 2005.

Corrêa, A.C.V., Políticas de Incentivo à Exportação de Software, Localização e Internacionalização de Software para Exportação - LISE, Florianópolis, nov. 2005. Disponível em: http://sl.geness.ufsc.br/lise/, acesso em: dezembro de 2005.

De Negri, J.A.; Salerno, M.S. (orgs.), Inovações, padrōes tecnológicos e desempenho das firmas industriais brasileiras, Brasília: IPEA, 2005.

Ferraz Filho, G.T.; Duarte, V.; Frick, S.; Roselino, J.E.; Matusita, A.P.; Almeida, N.; Alves, L.B.; Mittermayr, V., "A Experiência Exportadora do Setor de Software Brasileiro", Texto para Discussão n.137, Fundação Centro de Estudos em Comércio Exterior - FUNCEX , 1998.

Governo Federal, Diretrizes de Política Industrial, Tecnológica e de Comércio Exterior, nov., 2003.

Gutierrez, R.M.V.; Alexandre, P.V.M., "Complexo Eletrônico: Sistemas Integrados de Gestão", BNDES Setorial, Rio de Janeiro, n.21, p.105-139, mar., 2005.

MDIC, Acompanhamento da Política Industrial, Tecnológica e de Comércio Exterior. Brasília: Ministério do Desenvolvimento, Indústria e Comércio Exterior, 01/02/2005. Disponível em: http://www.desenvolvimento.gov.br/ Acesso em: dezembro de 2005.

Melo, P.R.S.; Castello Branco, C.E., "Setor de Software: Diagnóstico e Proposta de Ação para o BNDES”, BNDES Setorial, Rio de Janeiro, n.5, p.111-127, mar., 1997.

Menezes, E.; Ogushi, C.; Pataca, D.; Rios, J.M.; Marques, M.C.; Porto, C.C.S., "Política Industrial: Panorama Atual", FUNTELL: Projeto Sistema Brasileiro de Televisão Digital, Modelo de Implantação, OS: 40539, CPqD, maio, 2005.

OCDE, National Accounts and Economic Statistics: Report of 2004 OECD Software Survey, Statistics Directorate, $2004 a$. 
, Digital Delivery of Business Services, Working Party on the Information Economy, Directorate for Science Technology and Industry, $2004 \mathrm{~b}$.

Petit, D., "As Redes de Apoio ao Setor de Software e Serviços Correlatos e o seu Papel na Nova Política Industrial", in O Futuro da Indústria de Software: Perspectiva do Brasil, coletânea de artigos, Ministério do Desenvolvimento, Indústria e Comércio Exterior, Instituto Euvaldo Lodi, MDIC/STI, 2004.

Rocha, F., "As Atividades Produtoras de Software no Brasil", Texto para Discussão n.603, Instituto de Pesquisa Econômica Aplicada - IPEA, Rio de Janeiro, nov., 1998.

Roselino, J.E., "A Indústria de Software: o "modelo brasileiro" em perspectiva comparada", Tese de Doutoramento, Instituto de Economia, Universidade Estadual de Campinas, Campinas, 2006.

Roselino, J.E.; Gomes, R., "O Software e as Cadeias Produtivas Internacionalizadas", in Furtado, J. (org.), Globalização das cadeias Produtivas do Brasil, EdUFSCar, 2003.

Salatti, R.C., "Flexibilização do Tabalho em Empresas de Desenvolvimento de Sistemas", Dissertação de Mestrado, Instituto de Geociências, DPCT, UNICAMP, Campinas, 2004.

Saur, R., "Perspectivas e Projeções da Indústria Global de Software e Serviços", in, O Futuro da Indústria de Software: Perspectiva do Brasil, coletânea de artigos, Ministério do Desenvolvimento, Indústria e Comércio Exterior, Instituto Euvaldo Lodi, MDIC/STI, 2004.

Stefanuto, G.N.; Carvalho, R.Q., Perfil das Empresas Brasileiras Exportadoras de Software, DPCT/IG Unicamp, e Observatório Digital Softex, 2005.

Stefanuto, G.N., "O Programa Softex e a Indústria de Software no Brasil", Tese de Doutoramento, Instituto de Geociências, DPCT, UNICAMP, Campinas, 2004 .

Veloso, F; Botelho, A.J.; Tschan, T.; Amsden, A., "Slicing the Knowdge-Based Economy in Brazil, China and Índia: A Tale of 3 Software Industries", MIT Report, 2003. 